\title{
Pure 3D laparoscopic living donor right hemihepatectomy in a donor with separate right posterior and right anterior hepatic ducts and portal veins
}

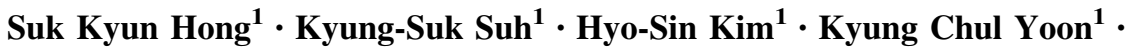 \\ Sung-Woo Ahn ${ }^{1}$ - Dongkyu Oh${ }^{1} \cdot$ Hyeyoung Kim ${ }^{1} \cdot$ Nam-Joon $\mathrm{Yi}^{1}$ • \\ Kwang-Woong Lee ${ }^{1}$
}

Received: 5 December 2016/Accepted: 20 March 2017/Published online: 14 April 2017

(c) The Author(s) 2017. This article is an open access publication

\begin{abstract}
Background Despite increases in the performance of pure laparoscopic living donor hepatectomy, variations in the bile duct or portal vein have been regarded as relative contraindications to this technique [1-3]. This report describes a donor with separate right posterior and right anterior hepatic ducts and portal veins who underwent pure laparoscopic living donor right hemihepatectomy, integrated with 3D laparoscopy and indocyanine green (ICG) near-infrared fluorescence cholangiography $[1,4,5]$.

Methods A 50-year-old man offered to donate part of his liver to his older brother, who required a transplant for hepatitis B-associated liver cirrhosis and hepatocellular carcinoma. Donor height was $178.0 \mathrm{~cm}$, body weight was $82.7 \mathrm{~kg}$, and body mass index was $26.1 \mathrm{~kg} / \mathrm{m}^{2}$. Preoperative computed tomography and magnetic resonance cholangiopancreatography showed that the donor had separate right posterior and right anterior hepatic ducts and portal veins. The entire procedure was performed under 3D laparoscopic view. Following intravenous injections of $0.05 \mathrm{mg} / \mathrm{kg}$ ICG, ICG near-infrared fluorescence camera was used to demarcate the exact transection line and determine the optimal bile duct division point.

Results The total operation time was $443 \mathrm{~min}$; the donor required no transfusions and experienced no intraoperative complications. The graft weighed $1146 \mathrm{~g}$ with a graft-to-
\end{abstract}

Electronic supplementary material The online version of this article (doi:10.1007/s00464-017-5535-8) contains supplementary material, which is available to authorized users.

Kyung-Suk Suh

kssuh2000@gmail.com

1 Department of Surgery, Seoul National University College of Medicine, 101 Daehak-ro, Jongno-gu, Seoul 110-744, Korea recipient weight ratio of $1.88 \%$. The optimal bile duct division point was identified using ICG fluorescence cholangiography, and the bile duct was divided with good patency without any stricture. The right anterior and posterior portal veins were transected with endostaplers without any torsion. The patient was discharged on postoperative day 8, with no complications.

Conclusion Using a 3D view and ICG fluorescence cholangiography, pure 3D laparoscopic living donor right hemihepatectomy is feasible in a donor with separate right posterior and right anterior hepatic ducts and portal veins.

Keywords Living donor liver transplantation .

Laparoscopy $\cdot$ Right hemihepatectomy $\cdot$ Indocyanine green

Compliance with ethical standards

Disclosures Suk Kyun Hong, Kyung-Suk Suh, Hyo-Sin Kim, Kyung Chul Yoon, Sung-Woo Ahn, Dongkyu Oh, Hyeyoung Kim, NamJoon Yi, and Kwang-Woong Lee have no conflicts of interest or financial ties to disclose.

Open Access This article is distributed under the terms of the Creative Commons Attribution 4.0 International License (http://crea tivecommons.org/licenses/by/4.0/), which permits unrestricted use, distribution, and reproduction in any medium, provided you give appropriate credit to the original author(s) and the source, provide a link to the Creative Commons license, and indicate if changes were made.

\section{References}

1. Suh KS, Hong SK, Yi NJ, Lee KW, Kim HS, Yoon KC et al (2016) Pure 3-dimensional laparoscopic extended right hepatectomy in a living donor. Liver Transpl 22:1431-1436

2. Soubrane O, Perdigao Cotta F, Scatton O (2013) Pure laparoscopic right hepatectomy in a living donor. Am J Transplant 13:2467-2471 
3. Han HS, Cho JY, Yoon YS, Hwang DW, Kim YK, Shin HK et al (2015) Total laparoscopic living donor right hepatectomy. Surg Endosc 29:184

4. Velayutham V, Fuks D, Nomi T, Kawaguchi Y, Gayet B (2016) $3 \mathrm{D}$ visualization reduces operating time when compared to high- definition 2D in laparoscopic liver resection: a case-matched study. Surg Endosc 30:147-153

5. Mizuno S, Isaji S (2010) Indocyanine green (ICG) fluorescence imaging-guided cholangiography for donor hepatectomy in living donor liver transplantation. Am J Transplant 10:2725-2726 